\title{
Réseau de lithothèques en Rhône-Alpes
}

$n^{\circ} 1288$

\section{Paul Fernandes}

\section{(2) OpenEdition \\ Journals}

Édition électronique

URL : http://journals.openedition.org/adlfi/15033

ISSN : 2114-0502

Éditeur

Ministère de la culture

Référence électronique

Paul Fernandes, « Réseau de lithothèques en Rhône-Alpes », ADLFI. Archéologie de la France -

Informations [En ligne], Rhône-Alpes, mis en ligne le 16 juillet 2015, consulté le 01 mai 2019. URL :

http://journals.openedition.org/adlfi/15033

Ce document a été généré automatiquement le 1 mai 2019.

(C) Ministère de la Culture et de la Communication, CNRS 


\section{Réseau de lithothèques en Rhône- Alpes}

$\mathrm{n}^{\circ} 1288$

\section{Paul Fernandes}

1 L'étude de l'origine des matières premières constitue une thématique de recherche commune à tous les préhistoriens. À la suite de travaux récents, il est possible de mettre en place une méthode de caractérisation renouvelée, fondée sur des supports multiscalaires (de la formation à silex au micro-faciès) et dynamiques (du gite primaire aux formations superficielles les plus distales, concept de la Chaîne évolutive). Des synergies ont été amorcées à différentes occasions (Orgnac 2004, tables rondes à Aurillac 2002, Lattes 2009, Lyon 2010...). L'ampleur des résultats acquis nous a convaincus de dépasser le cadre imposé par une vision régionale et l'idée que le silex est un matériau stable. À ce stade il apparaît essentiel de changer d'échelle, d'adapter le protocole au matériau, d'échanger, de diffuser les données et d'harmoniser les méthodes.

2 En 2013, le Groupe Silex dans le cadre du PCR a décidé de mieux structurer le projet en définissant les objectifs suivants : poursuivre l'élaboration d'un atlas des micro-faciès, géo-référencer les formations à silex à l'échelle du sud de la France, informer sur l'avancement de notre démarche, transmettre à tous les acteurs concernés les bases de données ainsi obtenues et entreprendre la formation à la caractérisation des silex.

Notre travail de fond consiste à créer un atlas des micro-faciès et des états de surface des principaux types marqueurs présents dans le sud de la France. Cette étape fondamentale vise à établir un fichier comprenant une description fine des aspects discriminants et une iconographie didactique à toutes les échelles.

4 Après plusieurs tâtonnements, une carte géo-référencée des principales formations à silex du sud de la France est en cours de réalisation. Elle propose une base nécessaire au développement d'études interrégionales sur la circulation des silex. Elle est le fruit d'une collaboration entre des acteurs impliqués dans la problématique de caractérisation de la provenance. Elle regroupe les résultats de leurs prospections systématiques ou ciblées dans six régions (Aquitaine, Auvergne, Languedoc-Roussillon, Midi-Pyrénées, Provence- 
Alpes-Côte-d'Azur, Rhône-Alpes). Elle intègre, en plus, le dépouillement d'un grand nombre de documents : les principaux articles et thèses traitant des formations à silex du sud de la France; plus de 200 fiches issues de la base de données du sous-sol BSS du BRGM, qui permettent de visualiser des logs ou des documents scannés; 529 cartes géologiques au $1 / 50000^{\mathrm{e}}$ et leurs notices. C'est l'ensemble de la formation contenant le ou les même(s) type(s) de silex qui est pris en compte, le terme de formation désignant un terrain possédant des caractères communs et constituant un ensemble cartographiable.

Pendant l'année 2013, certains membres du Groupe Silex ont organisé une table ronde à Nice en mars, afin d'identifier les acteurs et leurs champs d'investigation. À la suite de cette étape, une série de réunions a été coordonnée, pour présenter à tous les acteurs le bilan et les perspectives du projet de création d'un outil commun et supra-régional de cartographie et de caractérisation des silex.

Désormais, le projet «Atlas des silex du sud de la France » fédère le MCC (SRA : RhôneAlpes, PACA, Corse, Languedoc-Roussillon, Aquitaine, Midi-Pyrénées, Limousin, PoitouCharentes), plusieurs laboratoires du CNRS (CEPAM, PACEA, TRACES, LAMPEA), des universités (Nice, Bordeaux, Toulouse, Aix), plusieurs programmes collectifs de recherches (ETICALP: évolutions, transferts, inter-culturalités dans l'arc liguroprovençal : matières premières, productions et usages, du Paléolithique supérieur à l'âge du Bronze ancien; Réseau de Lithothèques en Rhône-Alpes; Espaces et Subsistance au Paléolithique moyen dans le sud du Massif central), la société Paléotime et l'Inrap. Il est en mesure de proposer, à terme, une diagnose harmonisée de tous les échantillons présents dans les différentes lithothèques conservées par les institutions énumérées.

À la suite de ces réunions il a été décidé à l'unanimité les points suivants :

8 Dans le but d'accélérer la réalisation du volet cartographique, il a été décidé d'engager un élève ingénieur géomaticien (encadré par les membres du groupe) pour constituer une carte géo-référencée de toutes les formations à silex dans le sud de la France. L'étudiant y consacrera un travail de fin d'études basé sur l'outil SIG, aboutissant à un mémoire intitulé «Pour une représentation dynamique des formations à silex». Ce travail s'articulera en quatre phases caractérisant notre démarche : compiler, archiver, analyser et contrôler.

9 Dans un premier temps, il faut constituer la donnée spatiale, et cela passera par une étape importante de numérisation des polygones précédemment identifiés et correspondants aux formations à silex. Le support géologique issu du BRGM sera notre base de travail afin d'assurer une interopérabilité future de nos couches. La notion d'inventaire des ressources siliceuses redéfinie vise donc, à terme, à ajouter au semis de points (indicateurs de prélèvements référencés au sein des lithothèques) des polygones représentant le potentiel minéral surfacique.

10 Devant l'ampleur d'une telle réalisation sur l'ensemble de l'aire d'étude considérée, il convient pour des raisons pratiques, de la scinder par secteurs qui serviront de zones-test pour engager des traitements spatiaux, en amont. Au fur et à mesure de cette élaboration, chaque polygone sera individualisé par un code permettant de corréler les données de caractérisation pétrographiques à partir d'un dénominateur commun. La description de chaque type sera jointe aux attributs du polygone de la formation correspondante. Pour optimiser cette jointure, une formalisation commune et bien circonscrite a été décidée et sera scrupuleusement respectée. Au final, chaque type recensé fait l'objet d'une table de 
données à 12 champs associée à une table des formations à 11 champs dans la base de données sur les formations à silex.

11 Ces données harmonisées devront intégrer les prospections et les recherches en laboratoire de l'ensemble des participants (plus de 100 personnes à l'heure actuelle), ainsi que toutes les données à acquérir dans le futur pour mieux définir encore le potentiel. Ces bases de données contiendront des photos à toutes les échelles (de la formation à l'échelle ultramicroscopique). Les références bibliographiques géologiques et archéologiques forment un champ à part. Les archéologues et géologues disposeront ainsi de fiches descriptives pour chaque type de silex et son encaissant. Elles serviront de support aux diagnoses analytiques si cela s'avère utile.

Une fois toutes les formations bien identifiées spatialement, une réflexion sur le traitement de mise en évidence des dynamiques de diffusion sera lancée. Ce travail sera aussi l'opportunité de commencer un traitement spatial visant à décrypter la dynamique de diffusion des échantillons géologiques, sachant que, par cet outil, chaque gîte ne sera plus considéré comme individuel et ponctuel mais intégré à un ensemble interdépendant et dynamique. À partir de sélections particulières sur la base de données couplées à des données d'ordre topographique, notre équipe cherchera à suivre ce cheminement pour les types qui nous intéressent en premier lieu. Les traitements les plus pertinents seront retenus pour la suite de l'exploitation. Pour le sud-est, il est envisagé d'initier ce travail par l'étude fine des silex du Bédoulien puisque c'est une matière première particulièrement importante dans les approvisionnements préhistoriques. Pour le sudouest, il faudra finaliser le travail sur les différents faciès appartenant aux familles des silex bergeracois, fumélois, santoniens et de Belvès.

Enfin, cette représentation étant prévue dans sa définition, le caractère évolutif du support SIG permettra de le compléter par des prospections terrain. Pour impulser cette opération, l'étudiant sera invité, si la durée convenue le lui permet, à proposer un outil de terrain qui assure le contrôle et la correction des données de la base en temps réel après validation.

14 L'Atlas des patrimoines est un outil cartographique du ministère de la Culture et de la Communication. Il offre un support idoine de diffusion des données géoréférencées, qui permet de garantir la pérennité des données, la traçabilité (propriétaire des données, gestionnaire, auteur, etc.) et l'interopérabilité. Pour cela, le projet de couche nationale sur les ressources en silex dans l'Atlas des patrimoines devra être validé par la Sousdirection de l'archéologie de la Culture. En outre, les données seront stockées sur des serveurs publics. Chaque chercheur ou groupe de chercheurs « contributeur » reste bien évidemment libre de publier ses résultats selon les modalités de son choix. La prochaine étape (début 2014) sera la présentation du projet en CNRA pour qu'il soit appuyé auprès de la Sous-direction de l'archéologie en vue de sa validation.

D'une manière globale, tous les membres s'accordent à dire que le Groupe Silex pourrait concrétiser son action au sein d'une école thématique du CNRS, d'un GDR et/ou d'un RTP en 2015. Un état des contacts avec l'INEE et une évaluation de l'intérêt de cet institut pour ce projet, seront demandés. Un format de type « école thématique » qui pourrait dans un premier temps être ouverte à des personnes académiques, et inclure, dans un deuxième temps, des doctorants est envisagé. 
16 L'élaboration de cet outil collaboratif permettant de mieux cerner les géoressources pour le sud de la France, si bien que cette entreprise constitue un objectif, désormais, à notre portée.

INDEX

Index chronologique : Préhistoire

Keywords : Methodology, flint, geo-referenced map

Mots-clés : méthode de caractérisation, silex

operation Projet collectif de recherche (PCR)

Index géographique : Rhône-Alpes

AUTEURS

PAUL FERNANDES

Paléotime 